\title{
The first observations of Ischnochiton (Mollusca, polyplacophora) movement behaviour, with comparison between habitats differing in complexity
}

\author{
Kiran Liversage ${ }^{\text {Corresp., }}{ }^{1}$, Kirsten Benkendorff ${ }^{2}$ \\ ${ }^{1}$ Estonian Marine Institute, University of Tartu, Tallinn, Estonia \\ 2 Marine Ecology Research Centre, Southern Cross University, Lismore, Australia \\ Corresponding Author: Kiran Liversage \\ Email address: kiran.liversage@ut.ee
}

Most species of Ischnochiton are habitat specialists and are almost always found underneath unstable marine hard-substrata such as boulders. The difficulty of experimenting on these chitons without causing disturbance means little is known about their ecology despite their importance as a group that often contributes greatly to coastal species diversity. In the present study we measured among-boulder distributional patterns of Ischnochiton smaragdinus, and used time-lapse photography to quantify movement behaviours within different habitat types (pebble substrata and rock-platform). In intertidal rock pools in South Australia, I. smaragdinus were significantly overdispersed among boulders, as most boulders had few individuals but a small proportion harboured large populations. I. smaragdinus individuals emerge from underneath boulders during nocturnal low-tides and move amongst the inter-boulder matrix (pebbles or rock-platform). Seventytwo percent of chitons in the pebble matrix did not move from one pebble to another within the periods of observation (55-130 minutes) but a small proportion moved across as many as 5 pebbles per hr, indicating a capacity for adults to migrate among disconnected habitat patches. Chitons moved faster and movement paths were less tortuous across rock-platform compared to pebble substrata, which included more discontinuities among substratum patches. Overall, we show that patterns of distribution at the boulder-scale, such as the observed overdispersion, must be set largely by active dispersal of adults across the substratum, and that differing substratum-types may affect the degree of adult dispersal for this and possibly other under-boulder chiton species. 
1 The first observations of Ischnochiton (Mollusca, polyplacophora) movement behaviour, with

2 comparison between habitats differing in complexity

3

4 Kiran Liversage ${ }^{1 *}$, Kirsten Benkendorff ${ }^{2}$

5

6 School of Biological Sciences, Flinders University, GPO Box 2100, Adelaide SA 5001, Australia

7

$8{ }^{1}$ Current address: Estonian Marine Institute, University of Tartu, Mäealuse 14, 12618, Tallinn,

9 Estonia

$10{ }^{2}$ Current address: Marine Ecology Research Centre, School of Environmental Science and

11 Management, Southern Cross University, Military Rd, Lismore, NSW, 2480, Australia

12 *Corresponding author: Email: kiran.liversage@ut.ee

13

14

15 Short running head: Movement behaviour of Ischnochiton

16

17

18

19

20

21

22

23 


\section{Abstract}

27 Most species of Ischnochiton are habitat specialists and are almost always found underneath unstable marine hard-substrata such as boulders. The difficulty of experimenting on these chitons without causing disturbance means little is known about their ecology despite their importance as a group that often contributes greatly to coastal species diversity. In the present study we measured among-boulder distributional patterns of Ischnochiton smaragdinus, and used timelapse photography to quantify movement behaviours within different habitat types (pebble substrata and rock-platform). In intertidal rock pools in South Australia, I. smaragdinus were significantly overdispersed among boulders, as most boulders had few individuals but a small proportion harboured large populations. I. smaragdinus individuals emerge from underneath boulders during nocturnal low-tides and move amongst the inter-boulder matrix (pebbles or rock-

37 platform). Seventy-two percent of chitons in the pebble matrix did not move from one pebble to another within the periods of observation (55-130 minutes) but a small proportion moved across

39 as many as 5 pebbles per hr, indicating a capacity for adults to migrate among disconnected habitat patches. Chitons moved faster and movement paths were less tortuous across rock-

41 platform compared to pebble substrata, which included more discontinuities among substratum 42 patches. Overall, we show that patterns of distribution at the boulder-scale, such as the observed 43 overdispersion, must be set largely by active dispersal of adults across the substratum, and that 44 differing substratum-types may affect the degree of adult dispersal for this and possibly other 45 under-boulder chiton species. 


\section{Introduction}

49

50 Dispersal of mobile benthic species can occur by a combination of movement processes

51 occurring as adults (Little 1989, Grantham et al. 2003) and by "supply-side" processes

52 (Underwood \& Fairweather 1989) for species with larval stages. Contributions of adult and

53 larval processes to dispersal have been measured for species with easily observable larval

54 processes (e.g. larval settlement/recruitment; Rowley 1989) or adult processes (e.g. movement of

55 slow-moving species on rock platforms exposed during low tide; Underwood \& Chapman 1989).

56 There are many species, however, that occur almost exclusively in cryptic/hidden habitats that

57 are not easily observed, such as underneath unstable hard-substrata. The species are mostly

58 hidden from view, and in order to observe them it is generally required to disturb the habitat

59 (Chapman \& Underwood 1996). Consequently, we have little information about their natural

60 dispersal capacities as adults. Our knowledge about intertidal invertebrate behavioural ecology

61 (see reviews by Grantham et al. 2003, $\mathrm{Ng}$ et al. 2013) would be improved by incorporating

62 under-boulder species, because the specialist species there often have high levels of rarity or

63 endemism (Benkendorff \& Przeslawski 2008, Chapman et al. 2009, Liversage 2015), and

64 ecological information is needed to inform conservation management.

65

66 One of the most widespread groups of boulder habitat specialists are chitons within the

67 Ischnochiton genus. While much research has focussed on movement behaviours of other chitons

68 that live on exposed (i.e. non-cryptic) rocky habitats (Thorne 1968, Chelazzi et al. 1983,

69 Chelazzi et al. 1987, Chelazzi et al. 1988) practically nothing is known of natural movement 
70 behaviours of Ischnochiton that are primarily associated with boulders. Palmer (2012) suggested

71 that patterns of among-boulder overdispersion could be explained by philopatric behaviour, with

72 chitons rarely dispersing from their natal boulders. Chapman (2002) observed high rates of

73 dispersal onto artificially deployed boulders, and questioned whether such dispersal may occur

74 by "drifting" or "crawling". Smith \& Otway (1997) and Jörger et al. (2008) noted that some

75 chitons readily drop off overturned boulders and fall into the water to be passively transported by

76 water motion. This was considered an "escape-response" that may affect the movements and

77 distribution of species that use this behaviour. Empirical data about movement ecology of

78 Ischnochiton is required to determine whether dispersal behaviours such as these are occurring in

79 reality and contributing to distributional patterns such as overdispersion. This pattern occurs

80 when large variation among replicates causes data to not approximate a Poisson distribution

81 (Richards 2008) and has been observed repeatedly for distribution data of other Ischnochiton

82 species (Grayson \& Chapman 2004, Liversage \& Benkendorff 2013).

83

84 The only direct observations of Ischnochiton movements are notes of movement occurring on 85 exposed rock surfaces, mostly nocturnally (Kangas \& Shepherd 1984). Using shell patterns to 86 identify individual chitons, Liversage et al. (2012) found that approximately two-thirds of the

87 individuals emigrate from their original boulder over three days, while an average of three new

88 chiton individuals move onto boulders. Similarly, in an intertidal cobble reef, McClintock et al.

89 (2007) marked and relocated a habitat-generalist chiton species (Sypharochiton pelliserpentis)

90 and found that the percentage of chitons that stayed under their original cobble after two tidal

91 cycles varied from $10 \%$ (small cobbles) to $45 \%$ (large cobbles). These studies suggest chitons

92 may move frequently across boulder habitat patches. The boulders/cobbles in these studies were, 
93 however, overturned for sampling and hence physically disturbed (Chapman \& Underwood

94 1996), so the relatively high levels of movement recorded may not fully reflect natural

95 movement patterns. To our knowledge no previous study has quantified undisturbed movement

96 patterns of any Ischnochiton species, which was our aim in this study.

98 Temperate boulder reefs of the south-eastern Australian intertidal-zone harbour populations of 99 Ischnochiton smaragdinus. This small chiton attains a maximum length of approximately $2 \mathrm{~cm}$ 100 and has a carnivorous diet of sponges, bryozoans and ascidians (Kangas \& Shepherd 1984). One

101 trait of this species that is atypical among most Ischnochiton is that some individuals become

102 active on the upper-surfaces of exposed-rock habitats nocturnally. Some other species of under-

103 boulder chitons that are more rare also share this behaviour (Kangas \& Shepherd 1984), but for

104 many parts of Australia, I smargdinus is the only species that can be observed in large

105 abundances exhibiting this behaviour.

106

107 The present study focused on I. smaragdinus, a common chiton in South Australian rock pools

108 which contain a variety of substrata including mostly pebbles (diameter 4-64mm), boulders

109 (diameter $>256 \mathrm{~mm}$ ) and rock platforms. First, we measured distributional patterns to test the

110 hypothesis that adult individuals are overdispersed among boulders, similarly to many other

111 representatives of Ischnochiton (Grayson \& Chapman 2004, Liversage \& Benkendorff 2013).

112 These distributions may be caused by movement behaviours. Accordingly, we measured

113 movement paths of chitons using time-lapse photography during nocturnal low tides. To

114 determine the generality of the finding from Liversage et al. (2012), that chitons migrate among

115 habitat patches that have been disturbed by sampling, we tested the hypothesis that chitons will 
116 not remain on individual habitat patches, but migrate amongst the boulders or pebbles that have

117 been left undisturbed (i.e. not overturned or moved). Measurements of chiton movements were

118 also made within pools that included rock-platform habitat, which includes fewer discontinuities

119 (i.e. interstices and areas of sand between adjacent hard-substrata) among habitat patches

120 compared to rock pools containing pebbles. We tested the hypothesis that variables including

121 speed and directionality were affected by the different habitat types.

122

123

124 Materials and Methods

125

126 Distributions and movement patterns of I. smaragdinus were measured during low tides at four 127 sheltered intertidal boulder fields on the Fleurieu Peninsula, South Australia during daylight. For 128 distribution measurements, 30 haphazardly selected boulders were overturned and numbers of 129 attached I. smaragdinus were counted during October 2007 at two sites (Myponga Beach -

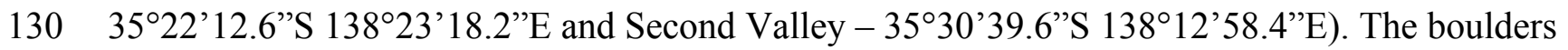

131 at both locations were approximately $30 \mathrm{~cm}$ long and $15 \mathrm{~cm}$ high, and were siltstone or sandstone.

132 Sampled boulders were separated from each other by approximately $1 \mathrm{~m}$. Frequency distributions

133 of chitons across boulders at each site were compared to a Poisson distribution (expected if

134 chitons are distributed randomly) using a one-sample Kolmogorov-Smirnov test. If patterns of

135 overdispersion produce non-random frequency distributions, this test will indicate a significant

136 difference between observed and expected (Poisson) distributions. 
138 Movement paths of I. smaragdinus were measured using time-lapse photography techniques

139 involving photography from above the water surface in randomly selected rock-pools. Because

140 no individuals were observed active on upper-surfaces of substrata during daytime, the

141 movement paths were measured at night, which was done during seven low-tide periods at two

142 sites at Myponga Beach between August and December 2006. One site (35'22'12.6”S

$143138^{\circ} 23^{\prime} 18.2^{\prime \prime} E$ ) had rock-pools with pebble substrata (Fig 1a); the mean length of pebbles was

144 measured from four rock-pools to be $4.14 \mathrm{~cm}(\mathrm{SE}=0.35)$ and all measured rock-pools had

145 pebbles of similar length (ANOVA $\mathrm{F}_{(3,36)}=0.88, P>0.25$ ). The pebbles were flattened with

146 their height about half their length, and were partially buried in sand. The second site

147 (35'22'01.9'S $\left.138^{\circ} 24^{\prime} 19.1^{\prime \prime} \mathrm{E}\right)$ had rock-pools with a substratum of unbroken rock-platform

148 (Fig. 1b). It is unknown if temporal effects may have occurred across the time the sites were

149 sampled, but the two habitat types were sampled in alternation and during similar weather

150 conditions to avoid confounding. Some nights were during full moon and others new moon

151 phases, but a preliminary comparison (ANOVA) done at one site during these two conditions

152 found no significant differences $(P>0.05)$ in any movement variables (see below for description

153 of variables). At each rock-pool, a camera (Olympus $\left.\mathrm{C} 5050^{\circledR}\right)$ was positioned on a tripod directly

154 above to photograph an area of approximately $50 \times 50 \mathrm{~cm}$. The camera took digital images at one

155 minute intervals using the flash set on minimum power. Flash photography did not appear to

156 affect the behaviour of the chitons, e.g. the distances moved immediately following the first

157 exposure to the flash were similar to those after 30 minutes of further exposures (ANOVA $F_{(1,62)}$

$158=2.20, P>0.1)$ and the numbers of chitons active outside of refuges also did not change

159 between those times (ANOVA $\mathrm{F}_{(1,13)}=0.04, P>0.75$ ). Periods of photography were initiated

160 when the tide had receded and there were no visual distortions of the substratum from moving 
161 water. Observations were ended when distortion from increasing water depth during the

162 advancing tide again prevented resolution of the substratum. This method provided an

163 observation time that varied from 55 to $130 \mathrm{~min}$.

164

165 Images were processed using Photoshop $\mathrm{CS}^{\circledR}$ imaging software. The locations of all chitons

166 within the rock-pool in the first image in a given time series was marked on a Photoshop ${ }^{\circledR}$

167 workspace layer separate from the image, then the next image in the time series was

168 superimposed on the first. The next image was adjusted in scale to offset the effects of changes

169 in water level (which magnifies or reduces the view of the substratum when viewed above the

170 water surface), and the subsequent position of all chitons was then added to the layer onto which

171 the initial positions were marked. This process was used for all subsequent images in the time

172 series until the entire movement paths of all chitons were delineated. To ensure each chiton

173 followed was an independent replicate, they were only included if no interaction occurred with

174 other chitons (i.e. direct contact or movement across another chiton's path). Studies using

175 photographs to measure habitat characteristics on larger boulder habitats have used techniques to

176 correct for the curvature of boulders (e.g. applying a corrective factor of $\approx 1.2$ to area

177 measurements from boulder edges; Liversage et al. 2012). While no distortion would be caused

178 when delineating movement paths leading around edges of pebbles, there may be distortion of

179 paths leading from edges over the pebble tops. However, because the pebbles were flattened in

180 shape, and the chitons were large (mean $0.64 \mathrm{~cm}$ ) in relation to the pebbles (mean $4.14 \mathrm{~cm})$, it was

181 not considered necessary in this case to apply any corrective adjustments.

182 
183 Three movement variables were measured as well as the length of each chiton. Net speed was

184 calculated as the total distance travelled divided by the total time observed. Maximum speed was

185 considered as the largest distance travelled by an individual in any five minute period. We

186 calculated the net:gross displacement ratio to provide an indication of the tortuosity of movement

187 paths, as done for sea stars (Swenson \& McClintock 1998), copepods (Buskey 1984), fish

188 (Parrish et al. 2002) and seals (Davis et al. 2001). This metric is calculated as net displacement

189 (the straight distance between the start and end point of a movement path) divided by gross

190 displacement (the actual distance travelled; Fig 1). A net:gross displacement ratio close to 0

191 indicates the movement path is highly tortuous, and most movement has not contributed to

192 dispersal away from the starting point. A value close to 1 indicates the path is straighter with

193 most movement having resulted in dispersal. The net:gross displacement ratio was measured

194 only for chitons that moved a minimum of $30 \mathrm{~mm}$ during the period of observation.

196 The number of chitons in each rock-pool was variable, so comparisons among treatments were

197 done with univariate PERMANOVA, using PRIMER v6 (Anderson \& Walsh 2013). We

198 considered substratum-type as a fixed factor and the different rock-pools as a random factor.

199 There was only one substratum type in each of the rock-pools, so the rock-pool factor was nested

200 in substratum-type. Attempts were made to find rock-pools with different substratum-types

201 within the same area, but appropriate substratum-types were only found separated spatially.

202 Distributional patterns vary over small spatial scales (i.e. among boulders) for Ischnochiton

203 (Grayson \& Chapman 2004, Liversage \& Benkendorff 2013), but few differences in other

204 among-boulder movement patterns have been found during comparisons of separate larger-scale

205 locations (Liversage et al. 2012). This suggests that spatial confounding between the sites can be 
206 considered unlikely in our comparisons between these substratum-types. The analyses used

207 Euclidean distances and 9999 permutations. Homogeneity of variances was tested with

208 PERMDISP, using medians, which in univariate analyses is equivalent to Levene's test

209 (Anderson et al. 2008). If the $P$ values of the random factor was $>0.25$, it was eliminated to

210 provide a more powerful test for the relevant null hypothesis (Underwood 1997).

\section{Results}

214

215 At our two study sites, most boulders had no Ischnochiton smaragdinus or only a small number

216 (1-3 individuals; Fig. 2) living under them. A small percentage of boulders harboured many

217 individuals, reaching up to 30 individuals at Myponga beach and 13 at Second Valley (Fig. 2).

218 These right-skewed frequency distributions differed strongly from the Poisson distributions

219 expected if chitons were distributed randomly (Myponga Beach Kolmogorov-Smirnov goodness220 of-fit test $P<0.001$; Second Valley $P<0.001$ ). These measurements were taken diurnally during

221 low tide, and all 143 individuals were sheltering underneath the boulders. None occurred in 222 exposed areas that were visible without overturning the substrata.

224 Movement paths of 113 individuals were analysed. Only 2 individuals did not move during the 225 observation periods (although they had likely moved recently into the exposed habitat). The 226 frequency of movement generally did not result in dispersal across substatum units (pebbles), but

227 a smaller proportion of individuals displayed more extensive dispersal (Fig. 3). Substratum-type

228 appeared to affect all movement variables measured (Table 1). Significantly lower speeds were 
229 observed in rock-pools with a pebble substratum, and this difference was particularly evident

230 regarding the maximum speeds attained (Fig. 4a). The fastest individual overall speed over a five

231 min period was $55 \mathrm{~cm} \cdot \mathrm{hr}^{-1}$ on a rock-platform surface. Although mean sizes of chitons varied

232 among random rock-pools, they did not vary between the two habitat types (Table 1), so this

233 variable did not affect differences in speed between fixed factor treatments.

234

235 The net:gross displacement ratio was significantly greater in rock-pools with a rock-platform

236 substratum (Table 1; Fig. 4b), indicating more directional, less tortuous movement paths.

237 Although chitons on pebble substrata often had highly tortuous paths, in no instances was it 238 observed that a given chiton returned to the same position where it had previously been resting.

241 Discussion

242

243 Movement patterns of mobile intertidal species vary from almost no movement (e.g. Branch 244 1975), to movement to and from a "home" position (e.g. Mackay \& Underwood 1977, Chelazzi

245 1990), to regular and widespread dispersal among habitat patches (e.g. Underwood 1977). The

246 results from the present study show for the first time that the undisturbed movement behaviour of

247 Ischnochiton smaragdinus involves dispersal among multiple patches of substrata. Many

248 individuals did not move across pebbles during the observation periods, but a small proportion

249 moved across as many as five within an hour. These individuals clearly did not remain in their

250 natal habitat, thus such behaviour is unlikely to explain patterns of overdispersion in this species.

251 No instances of chitons being "drifted" in the water were observed, indicating that adult dispersal 
252 occurs via "crawling", at least during low tide (Chapman 2002). This species does not exhibit the

253 behaviour of curling and detaching from disturbed boulders that other Ischnochiton do (Smith \&

254 Otway 1997, Jörger et al. 2008), and for these other species it is possible that more migration via

255 drifting occurs. I. smaragdinus may have migration behaviour similar to that of the intertidal

256 limpet Cellana tramoscerica which, like many chitons (Thorne 1968, Chelazzi et al. 1988),

257 sometimes displays homing behaviour, and it alternates between the homing behaviour and

258 randomly directed movement (Mackay \& Underwood 1977). The observations here could be

259 explained by I. smaragdinus individuals remaining in a "home" patch (i.e. pebble) for a certain

260 time and then subsequently moving quickly though adjacent patches. The methods in the

261 movement observations only assessed chitons that were active and many more individuals may

262 have been sheltering underneath the boulders and pebbles that were not observed, so the extent

263 of population-level migration or patch fidelity is unknown. It is also unknown how this species

264 may be moving during other contexts. For example, other forms of movement may be occurring

265 during day- or night-time high tides (although no individuals were observed moving during

266 daylight low tides) and for populations living deeper in the subtidal zone (Kangas \& Shepherd

267 1984).

268

269 Similar to other intertidal molluscs (Underwood \& Chapman 1989, Chapman \& Underwood

270 1994, Erlandsson et al. 1999, Underwood 2004), movements of I. smaragdinus appear to be

271 affected by topography of the substratum. A discontinuous layer of pebbles was associated with

272 reduced speed of movement and resulted in more convoluted movement paths. Complex

273 topographies are known to reduce movement speeds of some gastropods and result in faster

274 population turn-over rates in less complex areas with greater immigration and emigration 
275 (Underwood \& Chapman 1989). It may be advantageous for chitons to minimise time spent on

276 exposed rock-platforms to avoid predation, especially from brachyurans known to prey on

277 Ischnochiton (Mendonça et al. 2016), although brachyurans in South Australian rock-pools such

278 as Ozius truncatus may still be able to prey on chitons underneath pebbles by overturning them,

279 which was observed on one occasion to occur in the time-lapse photographs of this study.

280

281 The differences in dispersal capacity between the habitat types may also be useful in

282 understanding processes involving disturbance and restoration ecology. Disturbance in the form

283 of movement or overturning of boulders, or disruption of the under-boulder substratum, reduces

284 densities of chitons before a subsequent process of re-colonisation (Chapman \& Underwood

285 1996, Smith \& Otway 1997, Liversage et al. 2012). Similarly, when boulders are artificially

286 added to a shoreline for habitat restoration, it is important to know how species such as chitons

287 will colonise those boulders (Chapman 2012, 2013). The present study suggests adult

288 colonisation will occur most readily when the substratum among boulders is a rock-platform or

289 other surfaces of low complexity, which corresponds with patterns of colonisation of habitat

290 patches predicted from known movement patterns of other intertidal molluscs (Underwood \&

291 Chapman 1989, Chapman \& Underwood 1994, Erlandsson et al. 1999, Underwood 2004).

292

293 Smith \& Otway (1997) showed that I. smaragdinus is less sensitive to disturbance (boulder

294 overturning) compared to other chiton species. Nevertheless, our results indicate it has a highly

295 overdispersed distribution among boulders, similar to most other species of Ischnochiton

296 (Grayson \& Chapman 2004, Liversage \& Benkendorff 2013). Adults of other species may 
297 disperse in similar ways to I. smaragdinus, but less frequently, explaining why no other chitons

298 except Callochiton crocinus were seen during the present study.

299

300

301 Conclusions

302

303 This study shows that dispersal by adults of an Ischnochiton species occurs via active benthic

304 movement during noctural low tides, with the extent of dispersal dependent on the type of

305 substratum. This provides information necessary to predict responses to changes in habitat and

306 the potential to colonise new areas during habitat restoration (e.g. Chapman, 2012; Chapman,

307 2013). The novel methods used in this study of image-adjusted time-lapse photography from

308 above the water's surface will be useful in additional studies as there is increasing interest in

309 evaluating movements of mobile intertidal invertebrates in natural (Martinez et al. 2017) and

310 artificial (Browne \& Chapman 2014, Evans et al. 2016, Firth et al. 2016) rock-pools.

311

312

313 References

314

315 Anderson MJ, Gorley RN, Clarke KR (2008) PERMANOVA+ for PRIMER: Guide to Software

316 and Statistical Methods, Vol. PRIMER-E, Plymouth

317 Anderson MJ, Walsh DCI (2013) PERMANOVA, ANOSIM, and the Mantel test in the face of

318 heterogeneous dispersions: What null hypothesis are you testing? Ecological Monographs

$319 \quad 83: 557-574$ 
320 Benkendorff K, Przeslawski R (2008) Multiple measures are necessary to assess rarity in macro-

321 molluscs: a case study from southeastern Australia. Biodiversity and Conservation

322 $17: 2455-2478$

323 Branch GM (1975) Mechanisms reducing intraspecific competition in Patella spp.: migration, differentiation and territorial behaviour. Journal of Animal Ecology 44:575-600

325

326

327

328

329

330

331

332

333

334

335

336

337

338

339

340

341

342

Browne MA, Chapman MG (2014) Mitigating against the loss of species by adding artificial intertidal pools to existing seawalls. Marine Ecology Progress Series 497:119-129

Buskey EJ (1984) Swimming pattern as an indicator of the roles of copepod sensory systems in the recognition of food. Marine Biology 79:165-175

Chapman MG (2002) Early colonization of shallow subtidal boulders in two habitats. Journal of Experimental Marine Biology and Ecology 275:95-116

Chapman MG (2012) Restoring intertidal boulder-fields as habitat for "specialist" and “generalist” animals. Restoration Ecology 20:277-285

Chapman MG (2013) Constructing replacement habitat for specialist and generalist molluscs: the effect of patch size. Marine Ecology Progress Series 473:201-214

Chapman MG, Underwood AJ (1994) Dispersal of the intertidal snail, Nodilittorina pyramidalis, in response to the topographic complexity of the substratum. Journal of Experimental Marine Biology and Ecology 179:145-169

Chapman MG, Underwood AJ (1996) Experiments on effects of sampling biota under intertidal and shallow subtidal boulders. Journal of Experimental Marine Biology and Ecology 207:103-126

Chapman MG, Underwood AJ, Clarke KR (2009) New indices for ranking conservation sites using 'relative endemism'. Biological Conservation 142:3154-3162 
343 Chelazzi G (1990) Eco-ethological aspects of homing behaviour in molluscs. Ethology, Ecology

344 \& Evolution 2:11-26

345 Chelazzi G, Della Santina P, Parpagnoli D (1987) Trail following in the chiton Acanthopleura

346 gemmata: operational and ecological problems. Marine Biology 95:539-545

347 Chelazzi G, Focardi S, Deneubourg JL (1983) A comparative study on the movement patterns of 348 two sympatric tropical chitons (Mollusca: Polyplacophora). Marine Biology 74:115-125

349 Chelazzi G, Focardi S, Deneubourg JL (1988) Analysis of movement patterns and orientation mechanisms in intertidal chitons and gastropods. In: Behavioral adaptation to intertidal life. Springer US, p 173-184

352 Davis RW, Fuiman LA, Williams TM, Le Boeuf BJ (2001) Three-dimensional movements and

353

354 swimming activity of a northern elephant seal. Comparative Biochemistry and Physiology Part A: Molecular \& Integrative Physiology 129:759-770

Erlandsson J, Kostylev V, Williams GA (1999) A field technique for estimating the influence of surface complexity on movement tortuosity in the tropical limpet Cellana grata Gould. Ophelia 50:215-224

Evans AJ, Firth LB, Hawkins SJ, Morris ES, Goudge H, Moore PJ (2016) Drill-cored rock pools: an effective method of ecological enhancement on artificial structures. Marine and Freshwater Research 67:123-130

Firth LB, Browne KA, Knights AM, Hawkins SJ, Nash R (2016) Eco-engineered rock pools: a concrete solution to biodiversity loss and urban sprawl in the marine environment. Environmental Research Letters 11:094015

Grantham BA, Eckert GL, Shanks AL (2003) Dispersal potential of marine invertebrates in diverse habitats. Ecological Applications 13:s108-s116 
366 Grayson JE, Chapman MG (2004) Patterns of distribution and abundance of chitons of the genus

367 Ischnochiton in intertidal boulder fields. Austral Ecology 29:363-373

368 Jörger KM, Meyer R, Wehrtmann IS (2008) Species composition and vertical distribution of

369 chitons (Mollusca: Polyplacophora) in a rocky intertidal zone of the Pacific coast of

370 Costa Rica. Journal of the Marine Biological Association of the United Kingdom 88:807-

$371 \quad 816$

372 Kangas M, Shepherd SA (1984) Distribution and feeding of chitons in a boulder habitat at West

373 Island, South Australia. Journal of the Malacological Society of Australia 6:101-111

374 Little C (1989) Factors governing patterns of foraging activity in littoral marine herbivorous

375 molluscs. Journal of Molluscan Studies 55:273-284

376 Liversage K (2015) Habitat associations of a rare South Australian sea star (Parvulastra

377 parvivipara) and a co-occurring chiton (Ischnochiton variegatus): implications for

378 conservation. Pacific Conservation Biology 21:234-242

379 Liversage K, Benkendorff K (2013) A preliminary investigation of diversity, abundance, and

380 distributional patterns of chitons in intertidal boulder fields of differing rock type in

$381 \quad$ South Australia. Molluscan Research 33:24-33

382 Liversage K, Cole VJ, McQuaid CD, Coleman RA (2012) Intercontinental tests of the effects of

383 habitat patch type on the distribution of chitons within and among patches in intertidal

384 boulder field landscapes. Marine Biology 159:2777-2786

385 Mackay DA, Underwood AJ (1977) Experimental studies on homing in the intertidal patellid

$386 \quad$ limpet Cellana tramoserica (Sowerby). Oecologia 30:215-237

387 Martinez AS, Queiroz EV, Bryson M, Byrne M, Coleman RA (2017) Incorporating in situ

388 habitat patchiness in site selection models reveals that site fidelity is not always a 
consequence of animal choice. Journal of Animal Ecology:doi: 10.1111/1365-

391 McClintock JB, Angus RA, McClintock FE (2007) Abundance, diversity and fidelity of macroinvertebrates sheltering beneath rocks during tidal emersion in an intertidal cobble field: Does the intermediate disturbance hypothesis hold for less exposed shores with smaller rocks? Journal of Experimental Marine Biology and Ecology 352:351-360

Mendonça V, Vinagre C, Boaventura D, Cabral H, Silva ACF (2016) Chitons' apparent camouflage does not reduce predation by green crabs Carcinus maenas. Marine Biology

Ng TPT, Saltin SH, Davies MS, Johannesson K (2013) Snails and their trails: the multiple functions of trail-following in gastropods. Biological Reviews 88:683-700

Palmer ANS (2012) Spatial and genetic investigation of aggregation in Ischnochiton (Polyplacophora; Neoloricata; Ischnochitonina; Ischnochitonidae; Ischnochitoninae) species with different larval development. Austral Ecology 37:110-124

Parrish JK, Viscido SV, Grünbaum D (2002) Self-organized fish schools: an examination of 404 emergent properties. The Biological Bulletin 202:296-305

Richards SA (2008) Dealing with overdispersed count data in applied ecology. Journal of Applied Ecology 45:218-227

407 Rowley RJ (1989) Settlement and recruitment of sea urchins (Strongylocentrotus spp.) in a seaurchin barren ground and a kelp bed: are populations regulated by settlement or postsettlement processes? Marine Biology 100:485-494

410 Smith KA, Otway NM (1997) Spatial and temporal patterns of abundance and the effects of 411 disturbance on under-boulder chitons. Molluscan Research 18:43-57 
412 Swenson DP, McClintock JB (1998) A quantitative assessment of chemically mediated rheotaxis

413 in the asteroid Coscinasterias tenuispina. Marine and Freshwater Behaviour and

$414 \quad$ Physiology 31:63-80

415 Thorne MJ (1968) Studies on homing in the chiton Acanthozostera gemmata. Marine and

$416 \quad$ Freshwater Research 19:151-160

417 Underwood AJ (1977) Movements of intertidal gastropods. Journal of Experimental Marine

$418 \quad$ Biology and Ecology 26:191-201

419 Underwood AJ (1997) Experiments in Ecology: Their Logical Design and Interpretation Using

420 Analysis of Variance, Vol. Cambridge University Press, Cambridge

421 Underwood AJ (2004) Landing on one's foot: small-scale topographic features of habitat and the 422 dispersion of juvenile intertidal gastropods. Marine Ecology Progress Series 268:173-182

423 Underwood AJ, Chapman MG (1989) Experimental analyses of the influences of topography of

424 the substratum on movements and density of an intertidal snail, Littorina unifasciata.

425 Journal of Experimental Marine Biology and Ecology 134:175-196

426 Underwood AJ, Fairweather PG (1989) Supply-side ecology and benthic marine assemblages.

$427 \quad$ Trends in Ecology and Evolution 4:16-20

428

429

430

431 


\section{Table $\mathbf{1}$ (on next page)}

Univariate PERMANOVA comparing the length, movement speed, and tortuosity of movement paths for Ischnochiton smaragdinus individuals on a pebble or rock-platform substratum.

Measurements were taken from 7 randomly selected rock-pools. Substratum-type was a fixed factor and rock-pool was random and nested. PERMDISP tests determined if variances were significantly heterogenous. When the $P$-value of the random factor was $>0.25$ it was eliminated from the analysis to provide a more powerful test for the relevant null hypothesis (Underwood 1997). "-" designates eliminated term; *P $<0.05$; **P $<0.01$. 
1

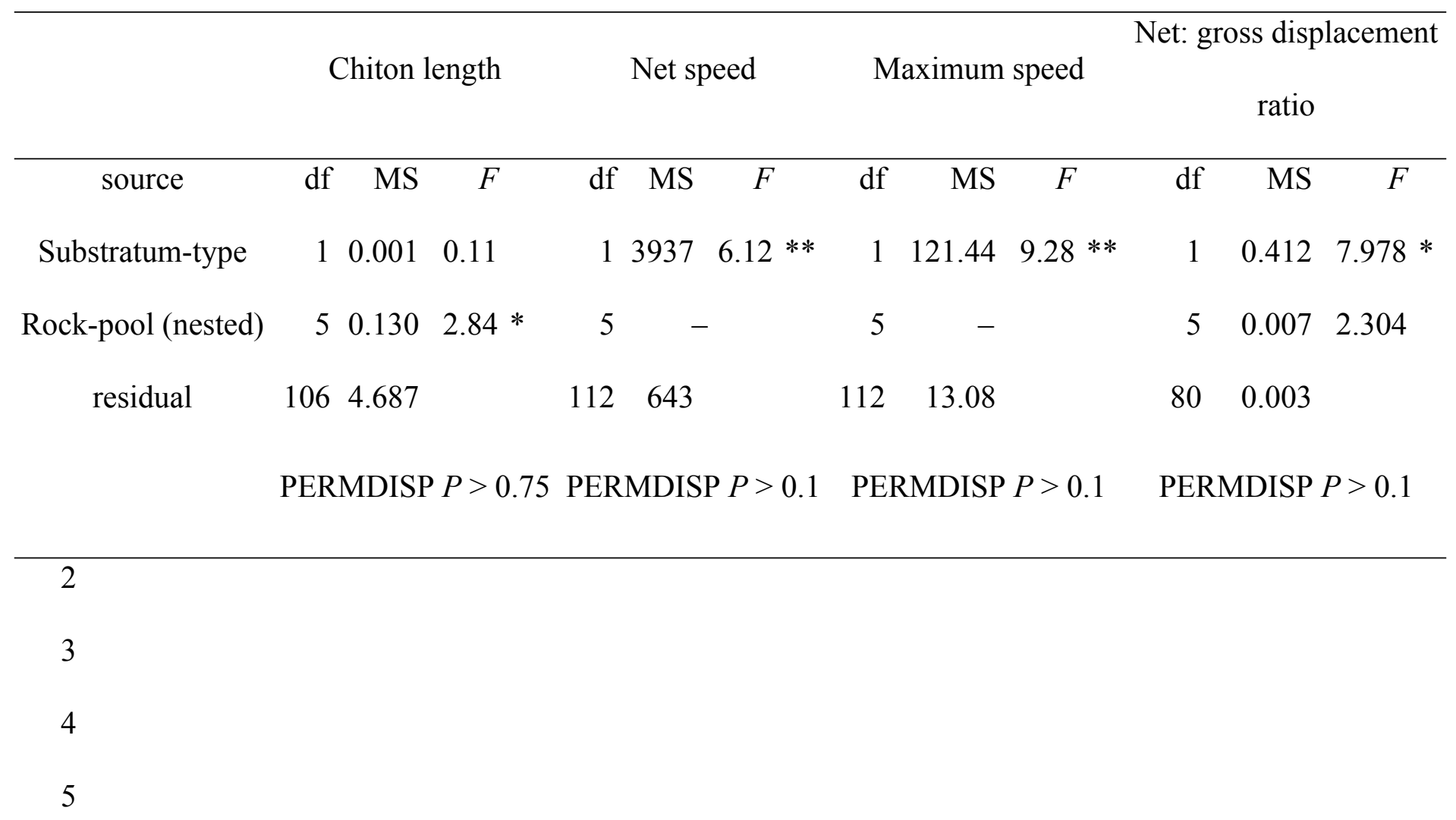




\section{Figure 1}

Representative movement paths of Ischnochiton smaragdinus.

Movement paths are from (A) pebble substratum (100 min) and (B) rock-platform substratum (60 $\mathrm{min}$ ) that were photographed from above the water surface (depth approx. $20-30 \mathrm{~cm}$ ).

The dashed blue line shown in (B) represents the Gross Displacement and the solid blue line indicates Net Displacement, with the ratio of these measures calculated to indicate the tortuosity of the movement path. Black lines at bottom right $=1 \mathrm{~cm}$.
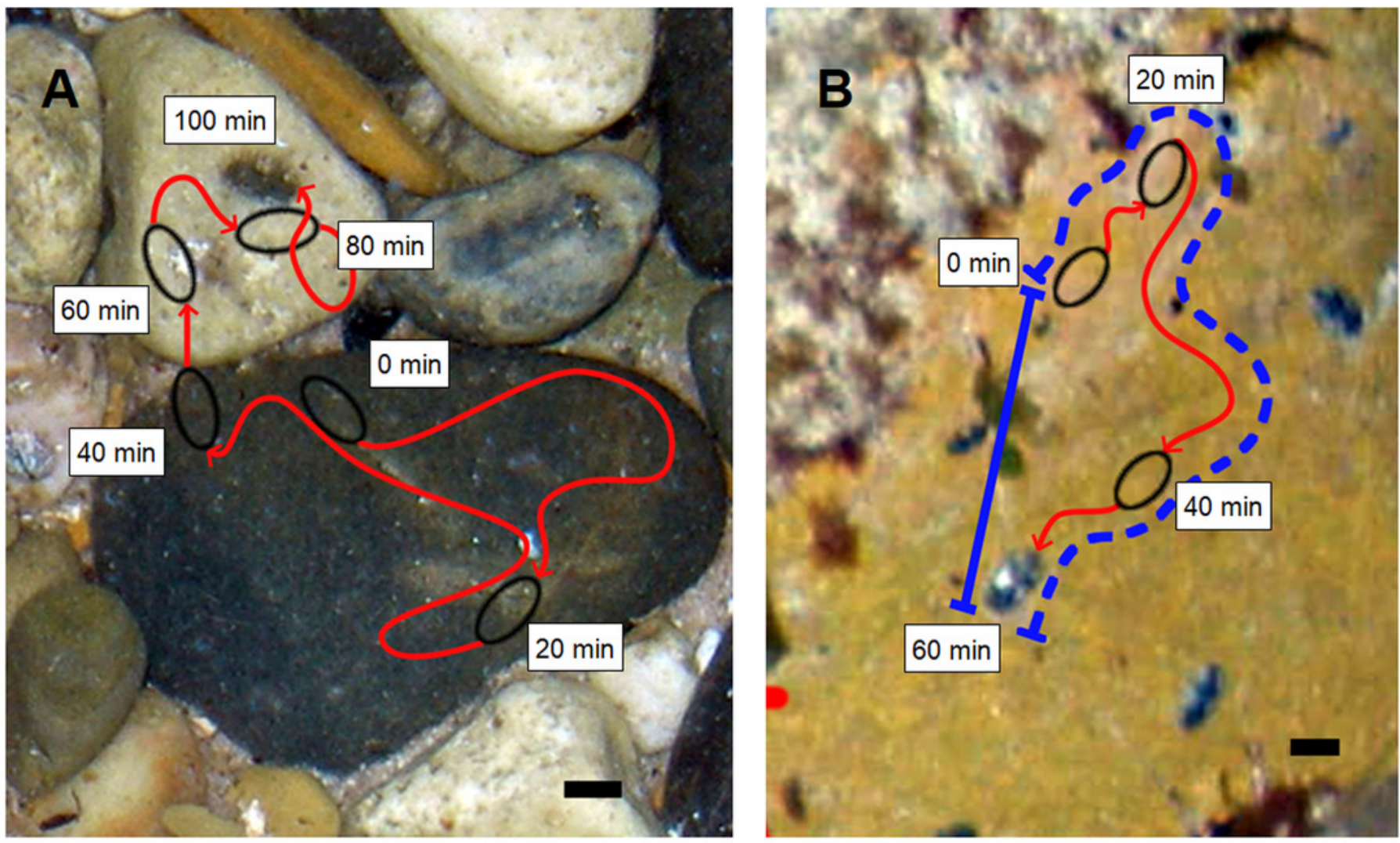
Figure 2

Frequency distributions of Ischnochiton smaragdinus among boulders.

Percentages are shown of the numbers of boulders that harboured different numbers of Ischnochiton smaragdinus individuals, from the sites Myponga Beach and Second Valley (30 boulders sampled per site).
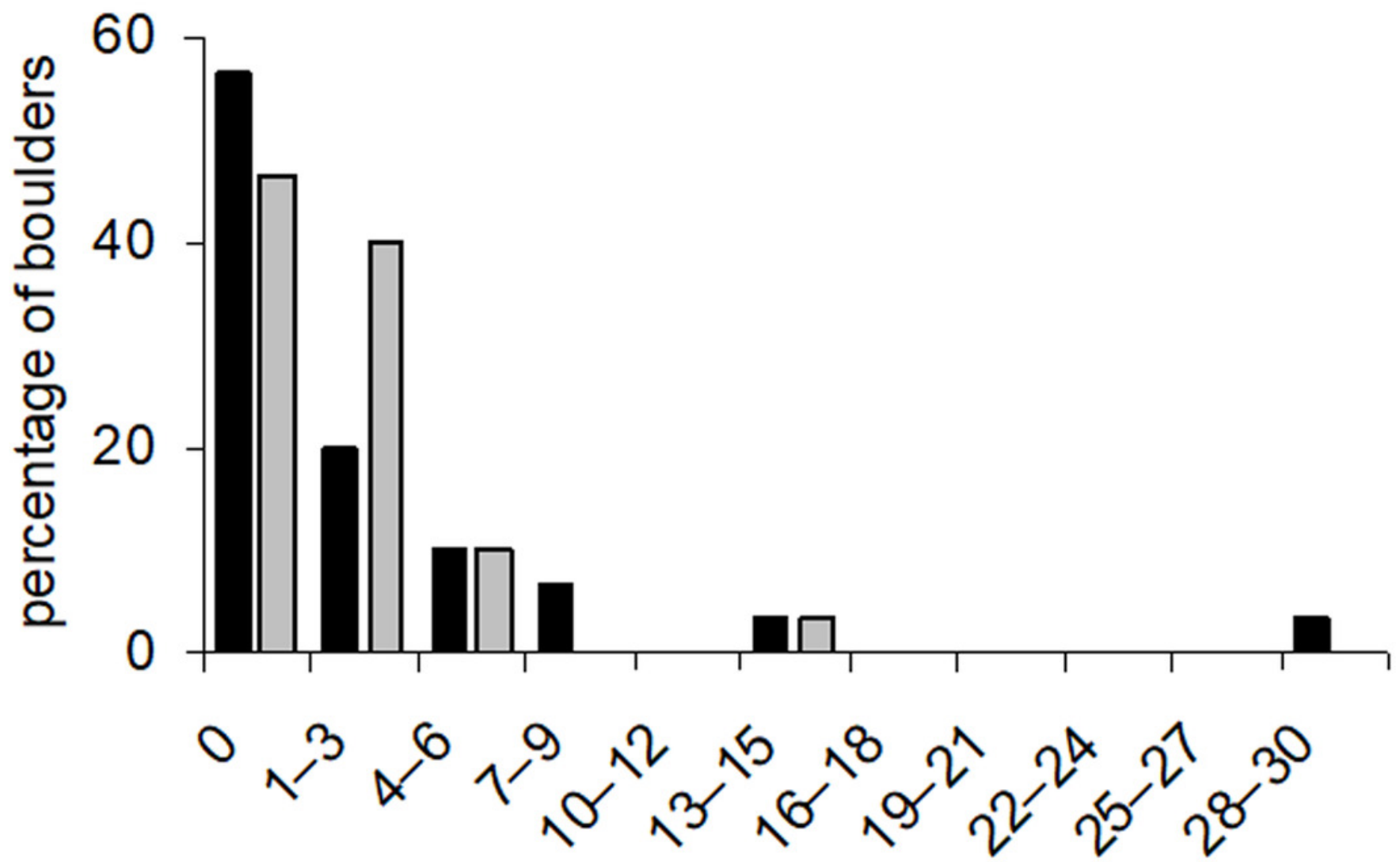

number of $I$. smaragdinus on boulder

- Myponga Beach $\square$ Second Valley 
Figure 3

Amounts of movement across pebble habitat patches.

Percentages of Ischnochiton smaragdinus from a total of 82 individuals that had different rates of movement across pebbles in four seperate rock pools with a pebble substratum.

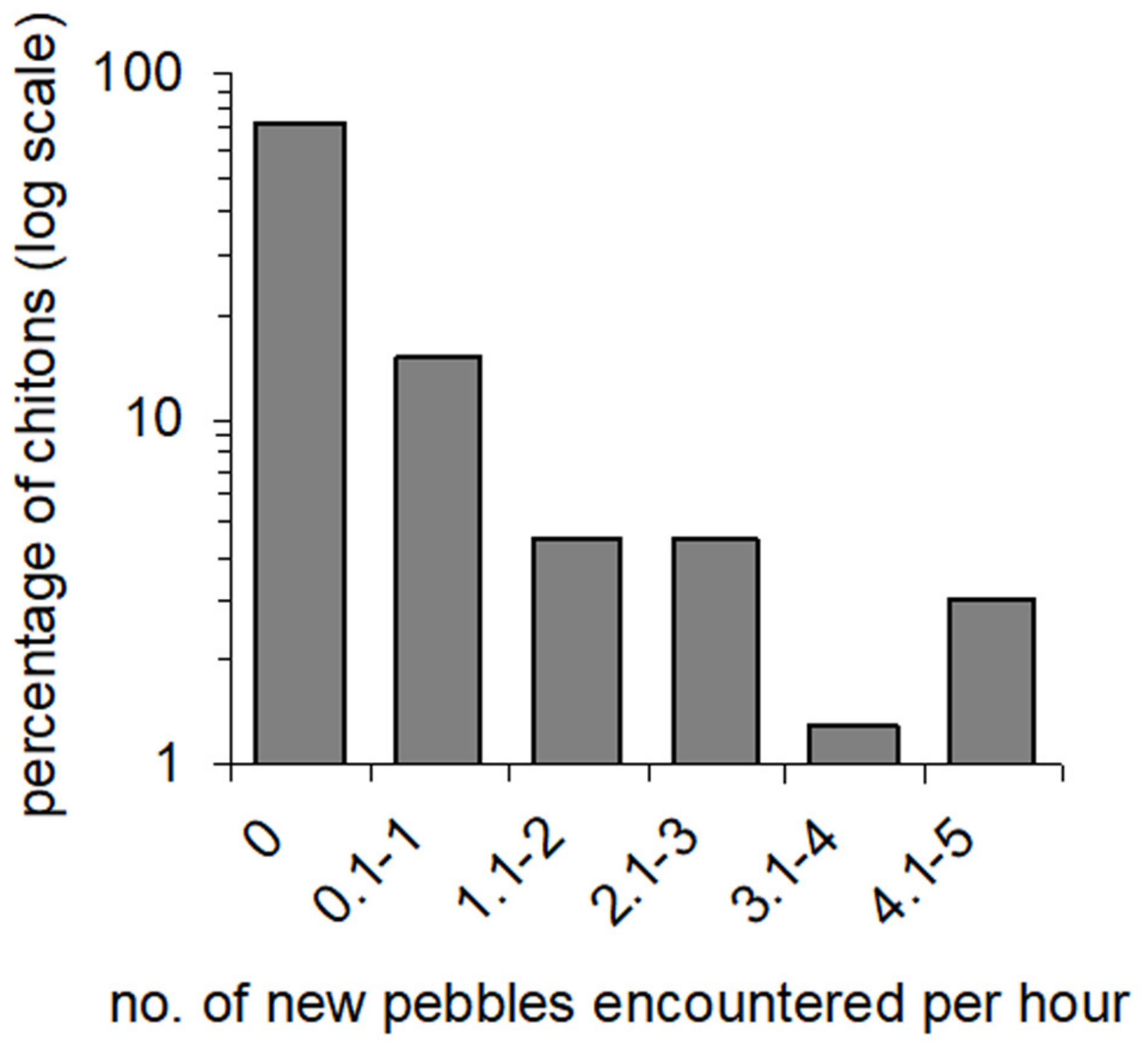


Figure 4

Movement characteristics of Ischnochiton smaragdinus in habitats of differing complexity.

Mean $( \pm S E)(A)$ speed of movement and $(B)$ tortuosity of the movement path (measured as net:gross displacement ratio; see Fig. 1). "Net speed" refers to the speed averaged over the entire observation period (55 - 130 minutes) and "max. speed" refers to fastest rate of movement by a chiton in any five minute period. Data are from four rock-pools with pebble substratum ( 82 chitons measured) and three with rock-platform substratum (32 chitons). *P $<0.05$.

(A)

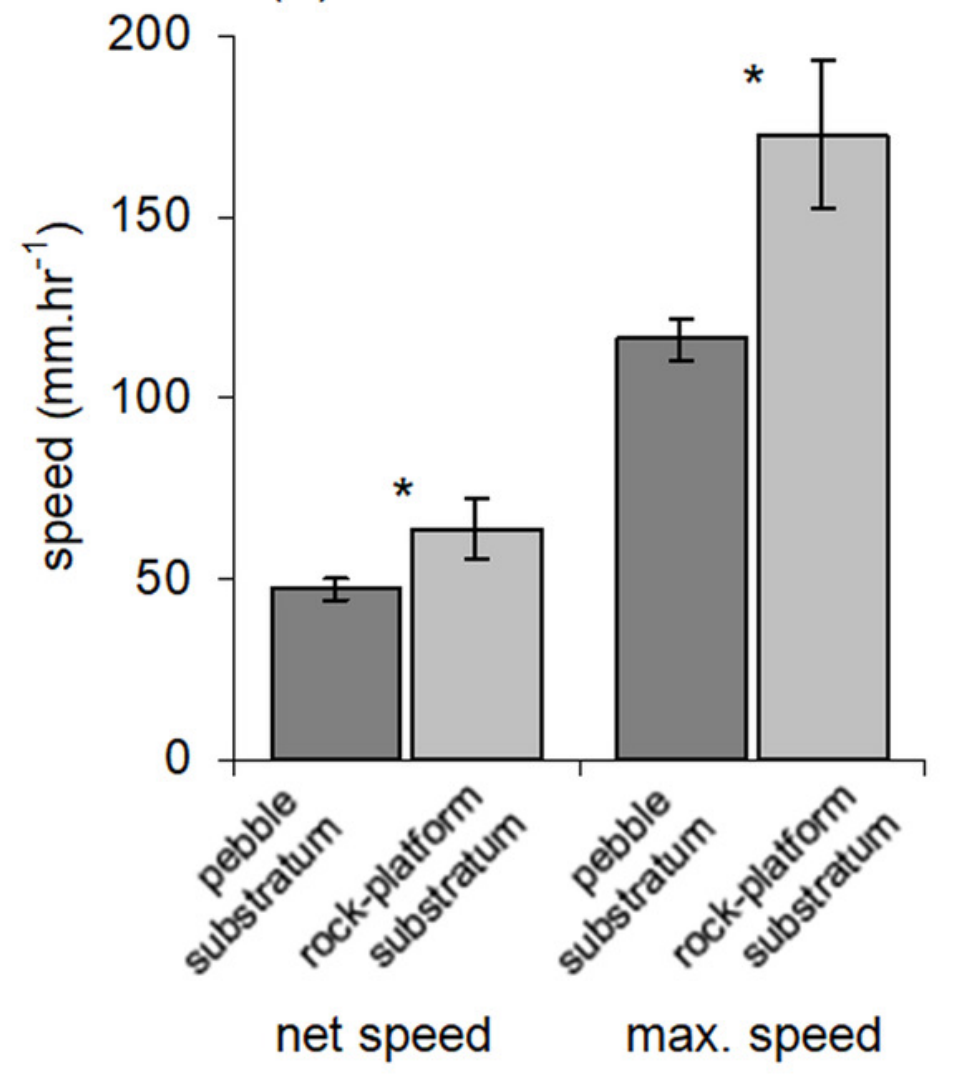

(B)

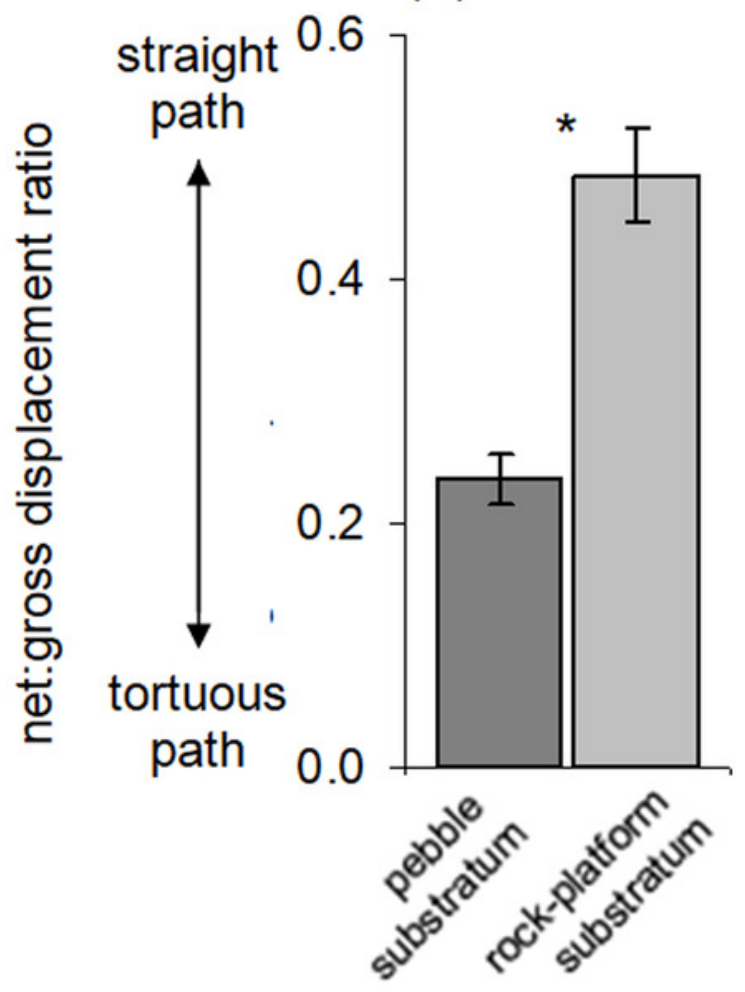

